\title{
Nucleoside Analogue Therapy Following One-Year Course of Hepatitis B Immunoglobulin in Preventing Hepatitis B Virus Reactivation after Living Donor Liver Transplantation
}

\author{
Naoki Kawagishi, ${ }^{1}$ Ikuo Takeda, ${ }^{2}$ Shigehito Miyagi, ${ }^{2}$ Kazushige Satoh, ${ }^{2}$ \\ Yorihiro Akamatsu, ${ }^{2}$ Satoshi Sekiguchi ${ }^{2}$ and Susumu Satomi ${ }^{2}$ \\ ${ }^{1}$ Division of Organ Transplantation, Tohoku University Hospital, Sendai, Miyagi, Japan \\ ${ }^{2}$ Division of Advanced Surgical Science and Technology, Graduate School of Medicine, Tohoku University, Sendai, \\ Miyagi, Japan
}

The combination therapy with hepatitis $B$ immunoglobulin (HBIG) and nucleoside analogue is well tolerated for the hepatitis B recipients after liver transplantation, but its cost is an important problem in these days. Here we report the efficacy of nucleoside analogue therapy following one-year course of HBIG plus nucleoside analogue after living donor liver transplantation (LDLT). Out of 103 LDLTs, we selected 14 recipients who received the post-transplant therapy against reactivation of hepatitis $B$ virus for more than 30 months. Those were eight patients with chronic hepatitis $B$, three with fulminant hepatitis, and three whose donors were positive for antibody to $\mathrm{HB}$ core antigen $(\mathrm{HBC})$. During two days after the operation, HBIG (40,000 units) was administered, and the serum level of antibody to HB surface antigen (HBs) was maintained at around $150 \mathrm{IU} / \mathrm{L}$ for one year by monthly administration of HBIG. After one year, HBIG was withdrawn. A nucleoside analogue was administered daily from just after LDLT, and it was continued up to the present. Among the 14 patients, two recipients had recurrence of hepatitis B. Three patients, including one patient with recurrence of hepatitis B, died due to hepatocellular carcinoma or its associated cirrhosis; namely, their deaths are unrelated to hepatitis B-related diseases. The remaining 11 patients are leading normal lives. In conclusion, nucleoside analogue therapy after one-year course of HBIG plus nucleoside analogue is feasible and cost-effective in preventing HBV reactivation. But the patients are still at risk of breakthrough and some patients may need continued prophylaxis with HBIG.

Keywords : lamivudine; entecavir; HBIG; living donor liver transplantation; HBV

Tohoku J. Exp. Med., 2010, 222 (4), 275-279. (C) 2010 Tohoku University Medical Press

In general, until the mid-90s, the patients' outcome after liver transplantation for hepatitis B virus (HBV)related liver disease was considered to be poor due to the absence of an effective prophylactic therapy (Samuel et al. 1993). But after the introduction of hepatitis B immunoglobulin (HBIG) combined with lamivudine, the outcome of the recipients improved dramatically. However, this combination therapy still has some limitations, such as the emergence of the YMDD mutant, hepatitis B surface antigen escape mutations, and the high cost of HBIG. As for the YMDD mutant, adefovir or entecavir therapy inhibits the replication of the virus by blocking reverse transcriptase even after liver transplantation (Lo et al. 2005). The amount of HBIG and the duration of the administration are controversial (Takaki et al. 2007).

In this article we report our experience with nucleoside analogue therapy following a one-year course of HBIG plus lamivudine after living donor liver transplantation (LDLT).

\section{Patients and Methods}

From July 1991 to November 2006, 103 LDLTs were performed in pediatric and adult patients with end-stage liver disease in the Division of Advanced Surgical Science and Technology, Graduate School of Medicine, Tohoku University. This program was approved by the ethics committee of Tohoku University Hospital, and the patients gave their informed consent for all procedures and therapies. Donors were selected among parents, brothers or sisters and spouses on the basis of liver function tests, serological markers of hepatitis, ABO blood group, graft / recipient size matching, lymphocyte cross-matching and HLA typing. The right lobe, left lobe or the left lateral segment of the liver was transplanted.

Among the 103 cases of LDLTs, we selected 14 recipients who received the post-transplant therapy against hepatitis B virus for more than 30 months (Table 1). Those were

Received August 27, 2010; revision accepted for publication November 9, 2010. doi: 10.1620/tjem.222.275

Correspondence : Naoki Kawagishi, Division of Organ Transplantation, Tohoku University Hospital, 1-1 Seiryou-machi, Aoba-ku, Sendai, 980-8574, Japan.

e-mail : kawan@med.tohoku.ac.jp 
Table 1. Demographic, clinical and virologic characteristics of recipients.

\begin{tabular}{|c|c|c|c|c|c|c|c|c|c|c|}
\hline \multirow{2}{*}{$\begin{array}{l}\text { Patient } \\
\text { No. }\end{array}$} & \multirow{2}{*}{$\begin{array}{c}\text { Age / } \\
\text { Gender }\end{array}$} & \multirow{2}{*}{$\begin{array}{c}\mathrm{Tx} \\
\text { Indication }\end{array}$} & \multirow{2}{*}{$\begin{array}{l}\text { MELD } \\
\text { Score }\end{array}$} & \multirow{2}{*}{$\begin{array}{l}\text { Donor } \\
\mathrm{HBcAb}\end{array}$} & \multirow{2}{*}{$\begin{array}{c}\text { Recipient } \\
\text { HBsAg } \\
\text { at Tx }\end{array}$} & \multirow{2}{*}{$\begin{array}{c}\text { HBV DNA } \\
\text { at Tx } \\
\text { (log copies } / \mathrm{mL} \text { ) }\end{array}$} & \multicolumn{2}{|c|}{ Nucleoside Analogues } & \multirow{2}{*}{$\begin{array}{l}\text { Observation } \\
\text { Period } \\
\text { (month) }\end{array}$} & \multirow{2}{*}{$\begin{array}{c}\text { Outcome } \\
(\mathrm{HBV} \\
\text { recurrence +/-) }\end{array}$} \\
\hline & & & & & & & Before Tx & After Tx & & \\
\hline 1 & $52 / \mathrm{M}$ & cirrhosis, HCC & 19 & - & + & 6.1 & $\mathrm{~L}$ & $\mathrm{~L}$ & 37 & dead $(-)$ \\
\hline 2 & $50 / \mathrm{M}$ & cirrhosis & 42 & + & + & - & $\mathrm{L}$ & $\mathrm{L}$ & 81 & alive $(-)$ \\
\hline 3 & $54 / \mathrm{F}$ & cirrhosis, HCC & 24 & + & + & 5.6 & $\mathrm{~L}$ & $\mathrm{~L}>\mathrm{E}$ & 41 & dead $(+)$ \\
\hline 4 & $43 / \mathrm{M}$ & cirrhosis, HCC & 9 & + & + & - & $\mathrm{L}$ & $\mathrm{L}$ & 61 & alive $(-)$ \\
\hline 5 & $53 / \mathrm{F}$ & cirrhosis & 22 & + & + & 5 & $\mathrm{~L}+\mathrm{A}$ & $\mathrm{L}+\mathrm{A}$ & 56 & alive $(-)$ \\
\hline 6 & $55 / \mathrm{M}$ & cirrhosis, HCC & 19 & - & + & - & - & $\mathrm{L}>\mathrm{E}$ & 51 & alive $(-)$ \\
\hline 7 & $46 / \mathrm{M}$ & cirrhosis & 27 & - & + & 2.8 & $\mathrm{~L}$ & L & 49 & alive $(-)$ \\
\hline 8 & $59 / \mathrm{M}$ & cirrhosis, $\mathrm{HCC}$ & 15 & - & + & 5 & $\mathrm{~L}+\mathrm{A}$ & $\mathrm{L}+\mathrm{A}$ & 41 & alive $(-)$ \\
\hline 9 & $45 / \mathrm{M}$ & fluminant hepatitis & 31 & - & - & - & $\mathrm{L}$ & L & 85 & alive $(-)$ \\
\hline 10 & $34 / \mathrm{M}$ & fluminant hepatitis & 41 & - & + & - & $\mathrm{L}$ & $\mathrm{L}$ & 84 & alive $(-)$ \\
\hline 11 & $31 / \mathrm{M}$ & fluminant hepatitis & 39 & - & + & 3.4 & $\mathrm{~L}$ & $\mathrm{~L}$ & 61 & alive $(-)$ \\
\hline 12 & $8 / \mathrm{F}$ & $\mathrm{BA}$ & 27 & + & - & - & - & $\mathrm{L}+\mathrm{A}$ & 204 & alive $(+)$ \\
\hline 13 & $63 / \mathrm{F}$ & cryptogenic, cirrhosis & 24 & + & - & - & - & $\mathrm{L}$ & 71 & alive $(-)$ \\
\hline 14 & $53 / \mathrm{F}$ & cirrhosis, $\mathrm{HCV}, \mathrm{HCC}$ & 14 & + & - & - & - & $\mathrm{L}$ & 32 & dead $(-)$ \\
\hline
\end{tabular}

MELD, model for end-stage liver disease; HCC, hepatocellular carcinoma; BA, biliary atresia; L, lamivudine; E, entecavir; A, adefovir; L $>$ E, convert from lamivudine to entecavir. In patients no. 9 and 10, their HBV DNAs were positive for a few days before Tx. In patient no. 12, she had no prophylaxis for hepatitis B virus reactivation after LDLT.

eight patients with chronic hepatitis B, three with fulminant hepatitis, and three recipients whose donors were positive for antibody to hepatitis B core antigen $(\mathrm{HBc})$. Eight patients were treated with lamivudine, two patients received adefovir in addition to lamivudine, and four patients did not receive a nucleoside analogue before LDLT (Table 1). HBV DNA was detected in six patients at the time of surgery. HBIG was administered everyday at the dose of 20,000 units during the operation and at the daily dose of 10,000 units for two days after it. The level of antibody to HB surface antigen (HBs) was maintained at around $150 \mathrm{IU} / \mathrm{L}$ for one year by the monthly administration of HBIG (Fig. 1). After one year, HBIG treatment was stopped but nucleoside analogue was administered daily from just after LDLT to the present. Lamivudine was administered orally at a dose of $100 \mathrm{mg} /$ body, adefovir dipivoxil was administered orally at a dose of $10 \mathrm{mg} /$ body, and entecavir was administered orally at a dose of $0.5 \mathrm{mg} /$ body. One of the three recipients whose donors were positive for antibody to $\mathrm{HBc}$ had been transplanted in 1993, but did not receive prophylactic therapy. The other two received the same prophylactic treatment as hepatitis B patients. The mean follow-up period was 68.1 months.

Tests for serum HBs, HB envelope antigen (HBe), antibody to $\mathrm{HBs}$, antibody to $\mathrm{HBe}$, and antibody to $\mathrm{HBc}$ were performed by commercially available chemiluminescent immunoassays (Abott Japan, Chiba, Japan). The serum HBV DNA level was measured using traction-mediated amplification assay (TMA) (SRL, Tokyo, Japan) or polymerase chain reaction (PCR) assay (SRL). The dynamic range of TMA and PCR assay was 3.7 to 8.7 and 2.6 to 7.6 $\log$ copies/mL, respectively.

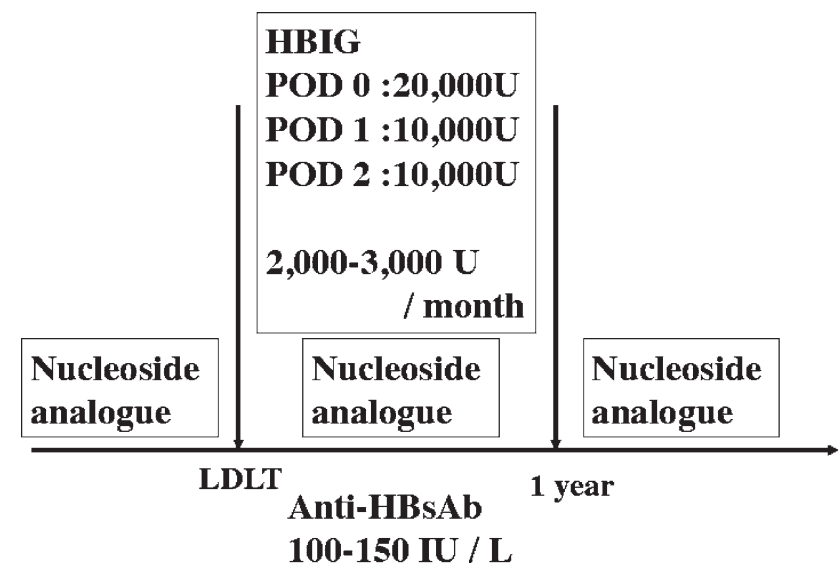

Fig. 1. Baseline antiviral prophylaxis for recurrent hepatitis B in Tohoku University Hospital.

Hepatitis B immunoglobulin (HBIG) was administered at the dose of 20,000 units during the operation and at the daily dose of 10,000 units for two days on POD 1 and 2 . The serum level of antibody to HBs was maintained from 100 to $150 \mathrm{IU} / \mathrm{L}$ for one year by the monthly administration of HBIG (2,000-3,000 U). One year after transplantation, HBIG administration was stopped but nucleoside analogue was continued.

HBIG, hepatitis B immunoglobulin; POD, post-operative day; LDLT, living donor liver transplantation; Anti$\mathrm{HBs} A b$, antibody to hepatitis B surface antigen.

The immunosuppressive regimen consisted of tacrolimus (TAC) or cyclosporine (CsA), methylprednisolone (MP), and mycophenolate mofetil (MMF). TAC was also administered orally 12 hours before transplantation at a dose of $0.075 \mathrm{mg} / \mathrm{kg}$, and from postoperative day (POD) 1 at a dose of $0.1 \sim 0.2 \mathrm{mg} / \mathrm{kg} /$ day via a nasogastric tube. The 
TAC dose was adjusted according to plasma trough levels. CsA was also administered orally 12 hours before transplantation at a dose of $4 \mathrm{mg} / \mathrm{kg}$, and from POD 1 at a dose of $3 \mathrm{mg} / \mathrm{kg} / \mathrm{day}$ by 4-hour drip infusion. The CsA dose was adjusted according to plasma trough levels. MP was administered at a dose of $20 \mathrm{mg} / \mathrm{kg} /$ day intravenously during the operation, and then tapered to $1 \mathrm{mg} / \mathrm{kg} /$ day within a week. Oral administration of MMF was started 1 or 2 weeks after LDLT at a dose of $20-30 \mathrm{mg} / \mathrm{kg} /$ day. Anti-CD25Ab (basiliximab, Novartis Pharmaceuticals Corporation, Basel, Switzerland) was also given to 9 recipients. Two $\mathrm{ABO}$-incompatible cases were included in this series. The immunosuppressive protocol for adult $\mathrm{ABO}$-incompatible recipients was described elsewhere (Kawagishi et al. 2007). Briefly, Rituximab was administered as prophylactic and plasma exchange was performed to reduce the level of anti$\mathrm{ABO}$ blood type antibodies. In the chronic period, most of the recipients were maintained only on TAC.

\section{Results}

Among eight recipients with cirrhosis (patients 1-8), six patients are doing well and leading normal lives, but two patients (patients 1 and 3) died (Table 1). The clinical histories of the two patients who died are summarized below.

Patient 1, a 52-year-old man, developed a liver abscess related to biliary stenosis three years and one month after LDLT, but he did not experience HBV reactivation. Patient 3 had the recurrence of hepatitis B [HB surface antigen (+), HBV DNA (+)] in three years and one month after LDLT. YMDD mutant was detected from the patient's serum. The patient had hepatocellular carcinoma (HCC) before transplantation. The HCC was detected as a single nodule, and its tumor diameter was $5 \mathrm{~cm}$ without vessel invasions. The patient was administered entecavir immediately after the reactivation, and the level of HBV-DNA decreased from 6.5 to $4.7 \log$ copies $/ \mathrm{mL}$. However, HCC had recurred in the liver, accompanied by metastases in the lungs, kidneys, and abdominal cavity at the time of HBV reactivation. She died four months after the reactivation of HBV. The relationship was not remarkable, she had received a liver graft from an ABO-incompatible donor, thus she had been administered a relatively high dose of immunosuppressors during the early period (i.e Rituximab, infusion therapy) after LDLT compared with the other recipients. But she never showed signs of antibody-mediated rejection.

On the other hand, no patient with fulminant hepatitis (FH) showed recurrence of hepatitis B. They are in good condition and have not presented any adverse effect of the nucleoside analogues such as thrombocytopenia, rhabdomyolysis or renal impairment.

We had three recipients whose donors were antibody to $\mathrm{HBc}$ positive. One recipient (patient 12), who underwent LDLT in the early 90s, did not receive HBIG prophylaxis because it was not well known that an antibody to $\mathrm{HBc}$ positive donor was a risk factor for hepatitis B after liver transplantation. This patient became HBs positive two years after LDLT, and the level of transaminases increased six years after LDLT, then lamivudine was administered. Emergence of a lamivudine-resistant YMDD mutant (YIDD) was detected two years after lamivudine administration, then adefovir dipivoxil was added on to lamivudine. HBV-DNA became negative, and the patient's serological HBV status was as follows: HBs positive, antibody to HBs negative, $\mathrm{HBe}$ negative, antibody to $\mathrm{HBe}$ negative, and antibody to HBc positive. The patient is leading a normal life. One patient (patient 14) died due to HCV related cirrhosis at 32 months after LDLT.

\section{Discussion}

The early experience with liver transplantation for hepatitis B virus related disease was that the majority of patients developed recurrent infection in the early postoperative period (Todo et al. 1991). However, over the last twenty years, the improvement of specific prophylactic therapy has almost settled the problem of recurrent hepatitis B. Namely, injection of high doses of HBIG and nucleoside analogue administration have contributed to prolong the survival of HBs positive recipients so that at present this is equal to that of recipients with other primary diseases. On the other hand, this therapy is very expensive leading to poor compliance. These factors led to the development of alternative strategies of prophylactic therapy for hepatitis B.

We demonstrated here the efficacy of nucleoside analogue therapy following one -year course of HBIG in preventing hepatitis B virus reactivation after LDLT. Although the rate of nucleoside analogue resistance after liver transplantation is usually low when HBIG is concomitantly administered, it seems that the risk of recurrence increases in case of nucleoside analogue therapy even after one-year course of HBIG. But in our series, the rate of recurrence was very low during the 42 months of follow up (median follow-up period). Some other groups also reported that lamivudine monotherapy after short-term HBIG was as effective as long-term lamivudine and HBIG combination therapy (Buti et al. 2003).

However, the risk of the viral breakthrough due to drug resistance still remains. Some authors reported after a longer follow up that hepatitis B recurred in $15 \%$ to $20 \%$ of the recipients who were switched to lamivudine monotherapy due to the emergence of the YMDD mutant (Buti et al. 2007). The risk of emergence of a lamivudine-resistant YMDD mutant increases with the duration of lamivudine treatment and serum HBV DNA level (Lo et al. 2005). And the patient with $\mathrm{HBV}$ before transplantation has higher risks for $\mathrm{HBV}$ reactivation in comparison to that with receiving a liver from a donor whose antibody to hepatitis B core antigen positive. Thus, the recipient of a graft from an antibody to $\mathrm{HBc}$ positive donor or with fulminant hepatitis constitutes the low risk group for the emergence of the YMDD mutant. If the YMDD mutant emerges, it will be necessary to switch from lamivudine to a combination of antiviral agents that will be a greater barrier to the develop- 
ment of resistance than lamivudine. In a recent randomized prospective study (Angus et al. 2008), 16 of 34 recipients receiving low-dose IM HBIG/ lamivudine prophylaxis for at least 12 months post-transplantation were switched to adefovir/ lamivudine combination therapy without HBIG, whereas the remaining recipients continued receiving the low-dose IM HBIG/ lamivudine therapy. At a median of 21 months post-switch, one of the 16 adefovir/lamivudine combination therapy without HBIG patients developed HBs positivity. Moreover, another of the 16 patients developed adefovir nephrotoxicity (Angus et al. 2008). This alternative prophylaxis saves costs significantly and improves the recipient's quality of life; however, it requires a prolonged follow-up period, further observation on the HBV breakthrough and adverse effects. In Japan, entecavir is the first line nucleoside analogue for the treatment of chronic hepatitis B because of its low rate of resistance; moreover, it is safe and effective for the treatment of Japanese adults with lamivudine-refractory chronic hepatitis B (Suzuki et al. 2008). In the field of liver transplantation, entecavir is expected to become the first line nucleoside analogue in the near future. In our series we are using entecavir for prophylaxis in one recipient and he has not shown signs of resistance so far. But the risk of developing multi-drug resistance with nucleoside and nucleotide antiviral agents should be always a concern.

The level of antibody to HBs titer after liver transplantation is also controversial. Historically, the maintenance dose of antibody to HBs was more than $500 \mathrm{IU} / \mathrm{L}$ or 1,000 IU / L in the early period of post-transplantation, and an antibody to HBs titer $>100 \mathrm{IU} / \mathrm{L}$ was usually recommended for lifelong maintenance (Roche and Samuel 2004). But its high cost and the patient's inconvenience cannot be ignored. The annual cost reduction of the second year after LDLT under our protocol is around 12,000 USD compared to the combination therapy. Our study offers a reliable and costeffective means for controlling HBV recurrence after LDLT, although the number of recipients is limited and more prospective studies are warranted.

Vaccination is a promising measure in some situations. For instance, if a recipient achieves an antibody to HBs response, thus eliminating the need for continued HBIG. In some reports, between $60 \%$ and $80 \%$ of recipients achieved an antibody to HBs titer of more than $10 \mathrm{IU} / \mathrm{L}$ following cessation of HBIG and active immunization with one to three courses of triple vaccination with recombinant IM HBV vaccine (Sánchez-Fueyo et al. 2000; Albeniz Arbizu et al. 2003). And another report revealed that after three vaccinations within six months, six out of 11 recipients (54.5\%) showed seroconversion and were set free from HBIG (Soejima et al. 2007). However, other studies with a second generation vaccine (Yamashiki et al. 2009) or the conventional $\mathrm{HBs}$ vaccine with concomitant HBIG administration (Rosenau et al. 2007) failed to accelerate antibody to HBs production. In our series three recipients underwent conventional HBs vaccination during the nucleoside analogue monotherapy, none of them achieved a high antibody to HBs titer. Hepatitis B vaccination for LDLT recipients is still controversial and remains experimental.

In conclusion, nucleoside analogue therapy after oneyear course of HBIG plus nucleoside analogue is feasible and cost-effective in preventing HBV reactivation. But the patients are still at risk of breakthrough and some patients may need continued prophylaxis with HBIG.

\section{References}

Albeniz Arbizu, E., Barcena Marugan, R., Oton Nieto, E., Carrera Alonso, E., Garcia Gonzalez, M., Moreno Garcia, J., de Vicente Lopez, E., Nuño Vazquez-Garza, J. \& Martin Davila, P. (2003) Prophylaxis of recurrent hepatitis B virus by vaccination after liver transplant: preliminary results. Transplant. Proc., 35, 1848-1849.

Angus, P.W., Patterson, S.J., Strasserb, S.I., McCaugan, G.W. \& Gane, E.J. (2008) A randomized study of adefovir dipivoxil in place of HBIG in combination with lamivudine as post-liver transplantation hepatitis B prophylaxis. Hepatology, 48, 14601466.

Buti, M., Mas, A., Prieto, M., Casafont, F., González, A., Miras, M., Herrero, J.I., Jardí, R., Cruz de Castro, E. \& García-Rey, C. (2003) A randomized study comparing lamivudine monotherapy after a short course of hepatitis B immune globulin (HBIg) and lamivudine with long-term lamivudine plus HBIg in the prevention of hepatitis B virus recurrence after liver transplantation. J. Hepatol., 38, 811-817.

Buti, M., Mas, A., Prieto, M., Casafont, F., González, A., Miras, M., Herrero, J.I., Jardi, R. \& Esteban, R. (2007) Adherence to lamivudine after an early withdrawal of hepatitis B immune globulin plays an important role in the long-term prevention of hepatitis B virus recurrence. Transplantation, 84, 650-654.

Kawagishi, N., Takeda, I., Miyagi, S., Satoh, K., Akamatsu, Y., Sekiguchi, S., Fujimori, K., Sato, T. \& Satomi, S. (2007) Management of anti-allogeneic antibody elimination by apheresis in living donor liver transplantation. Ther. Apher. Dial., 11, 319-324.

Lo, C.M., Liu, C.L., Lau, G.K., Chan, S.C., Ng, I.O. \& Fan, S.T. (2005) Liver transplantation for chronic hepatitis B with lamivudine-resistant YMDD mutant using add-on adefovir dipivoxil plus lamivudine. Liver Transpl., 11, 807-813.

Roche, B. \& Samuel, D. (2004) Evolving strategies to prevent HBV recurrence. Liver Transpl., 10, S74-S85.

Rosenau, J., Hooman, N., Hadem, J., Rifai, K., Bahr, M.J., Philipp, G., Tillmann, H.L., Klempnauer, J., Strassburg, C.P. \& Manns, M.P. (2007) Failure of hepatitis B vaccination with conventional $\mathrm{HBsAg}$ vaccine in patients with continuous $\mathrm{HBIG}$ prophylaxis after liver transplantation. Liver Transpl., 13, 367-373.

Samuel, D., Muller, R., Alexander, G., Fassati, L., Ducot, B., Benhamou, J. \& Bismuth, H.; Investigators of the European Concerted Action on Viral Hepatitis Study (1993) Liver transplantation in European patients with the hepatitis B surface antigen. N. Engl. J. Med., 329, 1842-1847.

Sánchez-Fueyo, A., Rimola, A., Grande, L., Costa, J., Mas, A., Navasa, M., Cirera, I., Sánchez-Tapias, J.M. \& Rodés, J. (2000) Hepatitis B immunoglobulin discontinuation followed by hepatitis B virus vaccination: A new strategy in the prophylaxis of hepatitis B virus recurrence after liver transplantation. Hepatology, 31, 496-501.

Soejima, Y., Ikegami, T., Taketomi, A., Yoshizumi, T., Uchiyama, H., Harada, N., Yamashita, Y. \& Maehara, Y. (2007) Hepatitis $\mathrm{B}$ vaccination after living donor liver transplantation. Liver Int., 27, 977-982.

Suzuki, F., Toyoda, J., Katano, Y., Sata, M., Moriyama, M., 
Imazeki, F., Kage, M., Seriu, T., Omata, M. \& Kumada, H. (2008) Efficacy and safety of entecavir in lamivudine-refractory patients with chronic hepatitis B: randomized controlled trial in Japanese patients. J. Gastroenterol. Hepatol., 23, 13201326.

Takaki, A., Yagi, T., Iwasaki, Y., Sadamori, H., Matsukawa, H., Matsuda, H., Shinoura, S., Umeda, Y., Miyake, Y., Terada, R., Kobashi, H., Sakaguchi, K., Tanaka, N. \& Shiratori, Y. (2007) Short-term high-dose followed by long-term low-dose hepatitis B immunoglobulin and lamivudine therapy prevented recurrent hepatitis B after liver transplantation. Transplantation., 83,
231-233.

Todo, S., Demetris, A.J., Van Thiel, D., Teperman, L., Fung, J.J. \& Starzl, T.E. (1991) Orthotopic liver transplantation for patients with hepatitis B virus-related liver disease. Hepatology, 13, 619-626.

Yamashiki, N., Sugawara, Y., Tamura, S., Kaneko, J., Matsui, Y., Togashi, J., Kokudo, N., Omata, M. \& Makuuchi, M. (2009) Double-dose double-phase use of second generation hepatitis $B$ virus vaccine in patients after living donor liver transplantation: Not an effective measure in transplant recipients. Hepatol. Res., 39, 7-13. 